\title{
A marker suitable for sex-typing birds from degraded samples
}

\author{
Deborah A. Dawson • Patricia Brekke • \\ Natalie Dos Remedios • Gavin J. Horsburgh
}

Received: 17 November 2014/ Accepted: 27 January 2015/Published online: 7 February 2015

(c) The Author(s) 2015. This article is published with open access at Springerlink.com

\begin{abstract}
A new primer set was developed for sex-typing birds, $Z 37 B$. This primer set was designed to amplify alleles of small size to render it suitable for sex-typing degraded samples, including shed feathers. This marker successfully sex-typed $50 \%$ of the species tested, including passerines, shorebirds, rails, seabirds, eagles and the brown kiwi Apteryx australis (allele size range $=81-103 \mathrm{bp}$ ), and is therefore expected to be suitable for sex-typing a wide range of species. Z37B sex-typed nondegraded samples (blood), degraded tissue (dead unhatched embryos, dead nestlings and museum specimens) and samples of low quantity DNA (plucked feathers and buccal swabs). The small amplicon sizes in birds suggest that this marker will be of utility for sex-typing feathers, swabs and degraded samples from a wide range of avian species.
\end{abstract}

Keywords AVES - Birds - Degraded samples $\cdot$ Feathers · Sex-typing $\cdot$ Non-invasive samples

Electronic supplementary material The online version of this article (doi:10.1007/s12686-015-0429-3) contains supplementary material, which is available to authorized users.

D. A. Dawson $(\bowtie) \cdot$ N. Dos Remedios · G. J. Horsburgh NERC Biomolecular Analysis Facility, Department of Animal and Plant Sciences, University of Sheffield, Western Bank, Sheffield S10 2TN, UK

e-mail: d.a.dawson@sheffield.ac.uk

P. Brekke

Institute of Zoology, Zoological Society of London, Regents Park, London NW1 4RY, UK

\section{Introduction}

In most bird species the sexes are morphologically indistinguishable, $\mathrm{ca} 50 \%$ of adults (60\% of passerines) and the majority of nestlings (Price and Birch 1996). Blood samples are often used for sex-typing birds; however, taking blood can cause stress, discomfort and may, on occasion, damage wings and/or introduce infection (Joint Working Group on Refinement 2001). It also requires training and appropriate permits. Therefore, less invasive techniques are preferred, especially when studying endangered species-for example, using shed feathers, museum specimens and swabs. Furthermore, studies of fertility and sex ratio require the ability to sex-type degraded tissue (e.g. unhatched eggs, Brekke et al. 2010). However, allelic dropout can occur when attempting to PCR-amplify large products from degraded samples (Toouli et al. 2000) and dropout causes errors in sex-typing (Robertson and Gemmell 2006). We therefore attempted to develop a primer set that amplifies small PCR products $(<150 \mathrm{bp})$ on both the $\mathrm{W}$ and $\mathrm{Z}$ chromosomes to enable sex-typing of degraded samples.

\section{Methods}

Following Dawson et al. (2010), a zebra finch Taeniopygia guttata EST microsatellite sequence DV945670 (Replogle et al. 2008) was identified with strong homology to the chicken Gallus gallus $\mathrm{Z}$ chromosome. We created a consensus sequence from these homologous sequences using MEGA3 (Kumar et al. 2004) and designed a primer set using PRIMER3 v0.4.0 (Rozen and Skaletsky 2000). Both the forward and reverse primers were $100 \%$ identical to both the zebra finch $\mathrm{Z}$ and chicken $\mathrm{Z}$ chromosomes (no 
homologous $\mathrm{W}$ chromosome sequence was available). In order to create a primer set suitable for amplifying degraded samples, we designed the primer set to amplify a small product $(<150 \mathrm{bp})$ whilst avoiding the use of degenerate bases (Table 1). Primer sequences, melting temperatures and the expected and observed allele sizes in zebra finch and chicken are provided (Table 1). The locus (DV945670) was homologous to mRNA sequences of the guanine nucleotide binding protein (G protein), q polypeptide (GNAQ) present in many taxa. Both primer sequences were $100 \%$ identical to $9 / 10$ birds assessed, including passerines, penguins and other seabirds, eagle, duck and chicken (details provided in the footnotes of Table 1).

Genomic DNA was extracted from non-degraded samples (bird blood, blood slides), samples of low quantity (shed and plucked feathers, buccal swabs), degraded tissue [dead embryos from unhatched eggs, dead nestlings, museum (toe pad) samples] and crocodile skin using an ammonium acetate protocol (Richardson et al. 2001) or commercial kits (for the museum specimens and mouth swabs). Full details of the samples and extraction methods are provided in Supplementary Table 1. The primer set was tested by sex-typing individuals of 42 avian species including one ratite, the brown kiwi Apteryx australis (25 families and 15 orders; Table 2), and the saltwater crocodile Crocodylus porosus. Individuals of known sex (both females and males) were included for 40 of the bird species (for two species known females were available but no known males; Table 2). Sexes were previously identified based on morphology, behaviour and/or sex-typing markers (Table 2). PCR reactions were performed in $2-\mu \mathrm{l}(10-\mu \mathrm{l}$ for museum samples) volumes containing ca $10 \mathrm{ng}$ of lyophilised genomic DNA, 1 or $5 \mu$ of QIAGEN Multiplex PCR Master Mix and $0.2 \mu \mathrm{M}$ of each primer (with the forward primer fluorescently labelled with HEX). PCR amplification was performed using a DNA Engine Tetrad thermal cycler. PCR amplification conditions were $95{ }^{\circ} \mathrm{C}$ for $15 \mathrm{~min}$; followed by 35 cycles of $94^{\circ} \mathrm{C}$ for $30 \mathrm{~s}, 56^{\circ} \mathrm{C}$ for $90 \mathrm{~s}, 72^{\circ} \mathrm{C}$ for $1 \mathrm{~min}$, and finally $60{ }^{\circ} \mathrm{C}$ for $30 \mathrm{~min}$. PCR products were loaded on a 48-capillary ABI 3730 DNA Analyzer and genotypes assigned using GENEMAPPER software (Applied Biosystems).

\section{Results}

All 42 bird species tested amplified, as did the saltwater crocodile (amplicons $=81-110 \mathrm{bp}$, saltwater crocodile $=110 \mathrm{bp} ; \quad$ Table 2$). \quad$ Twenty-one $\quad$ species $(50 \%)$ were successfully sexed: including passerines, shorebirds, rails, seabirds, eagles and the brown kiwi (Table 2). In all species sexed, the diagnostic $\mathrm{W}$ allele (81-92 bp) was smaller than the $Z$ allele (92-100 bp; Table 2). The difference in size between the $\mathrm{W}$ and $\mathrm{Z}$ alleles within a species was small (2-19 bp, Table 2) and resolving this difference required an ABI DNA Analyzer.

Individuals were successfully sex-typed from the degraded tissues including unhatched embryos, dead nestlings and museum toe-pads (of the hihi Notiomystis cincta), and from samples of low-quantity DNA, i.e. plucked feathers (hihi, northern fulmar Fulmarus glacialis) and buccal swabs (corncrake Crex crex; Table 2). Individuals whose DNA was extracted from non-degraded blood samples were also successfully sex-typed (Table 2). Z37B successfully sex-typed individuals when included as part of a microsatellite multiplex set (hihi and corncrake; PB unpublished data).

Many species displayed a single allele (i.e. of same size) in both sexes and could therefore not be sexed (43\%; Table 2), probably due to failure of the $\mathrm{W}$ locus to amplify (or possibly a lack of difference in size between the $\mathrm{Z}$ and $\mathrm{W}$ amplicons). Eight species (19\%) displayed polymorphism in the $\mathrm{Z}$ locus and for three of these species $(7 \%)$ all females were homozygous - suggesting that the $\mathrm{W}$ locus failed to amplify (probably due to primer-W chromosome base mismatches; Table 2). In some species, the $\mathrm{W}$ locus might require a lower PCR annealing temperature to amplify, such as $50{ }^{\circ} \mathrm{C}$. We recommend the use of Qiagen Multiplex Master Mix for PCR sex-typing because it more often enables amplification even when there are some target-primer base mismatches (DAD unpublished data). Although not causing error here, $\mathrm{Z}$ (and/or W) polymorphism can lead to error when interpreting sexes, unless a second sex-typing marker and/or known sexes are included (Dawson et al. 2001, Robertson and Gemmell 2006).

Marker $Z 37 B$ is of utility for sex-typing degraded samples. It provides an alternative marker to validate sextyping data. Most of the passerine species tested could be sex-typed with this marker, suggesting it will be of utility for sex-typing many of the ca 5,000 species in this order. In addition, the successful sex-typing of non-passerines including shorebirds, rails, seabirds, eagles and kiwi, suggests $Z 37 B$ will be of utility in a wide range of species. 


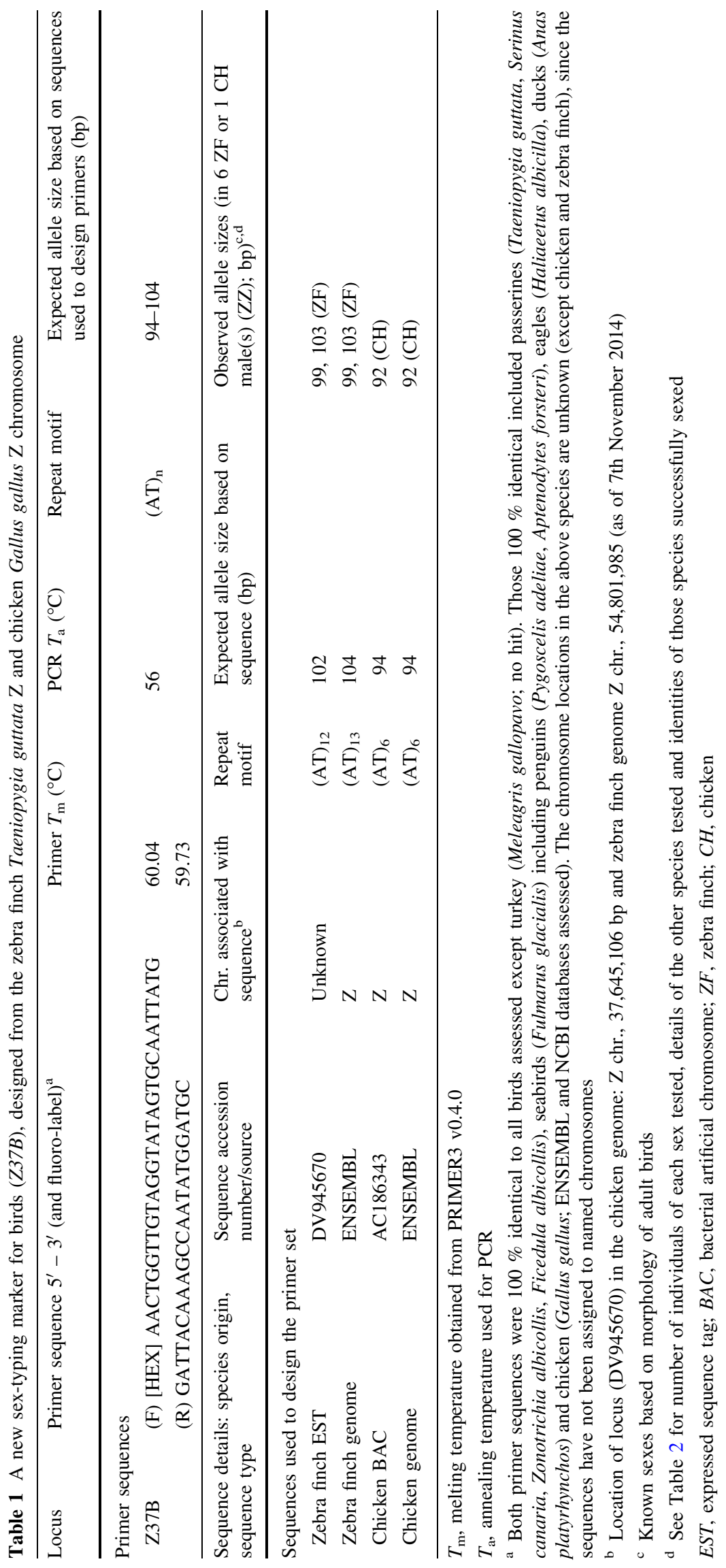




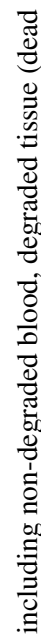

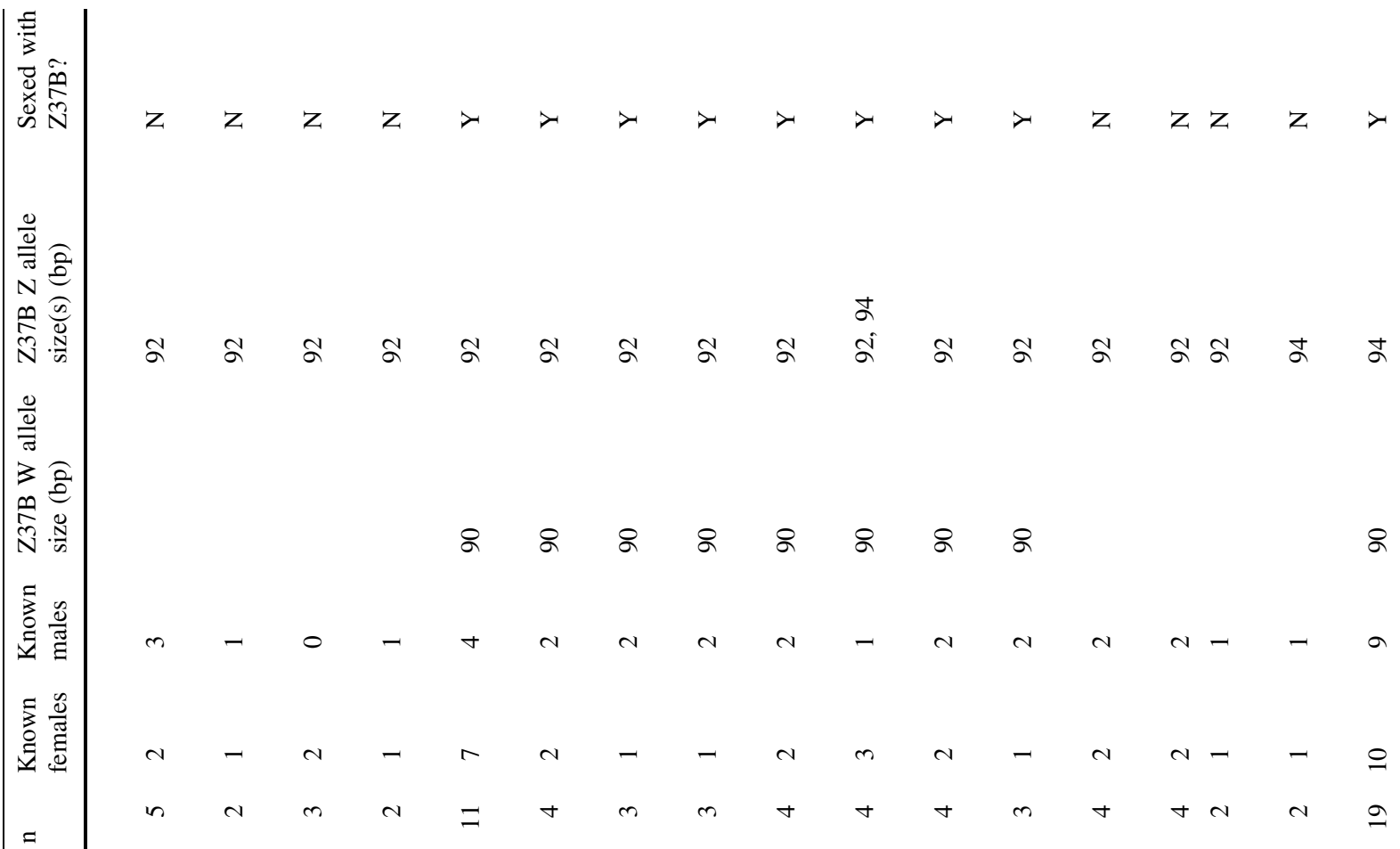
西

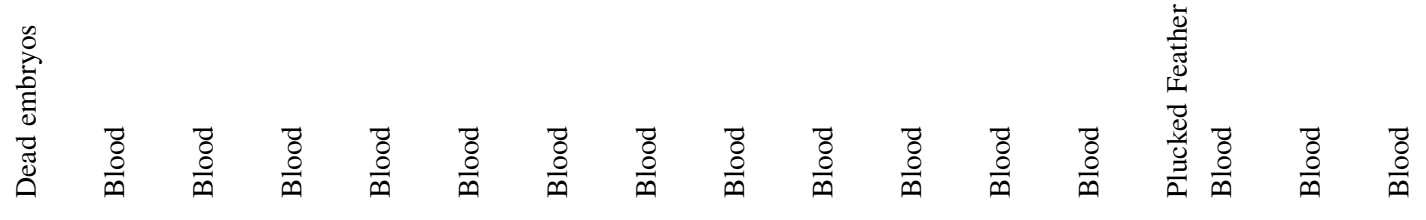
눙

\section{3}




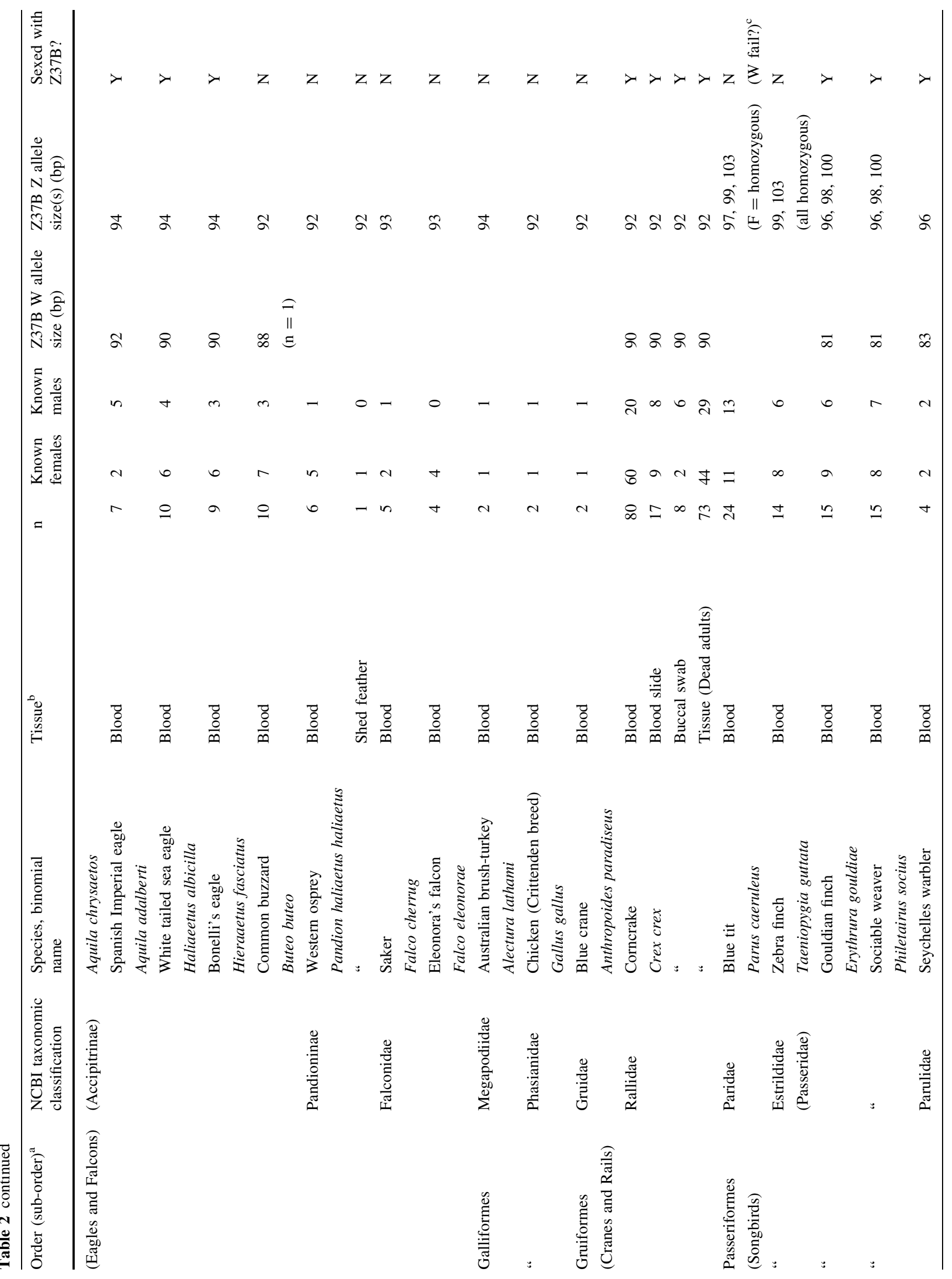




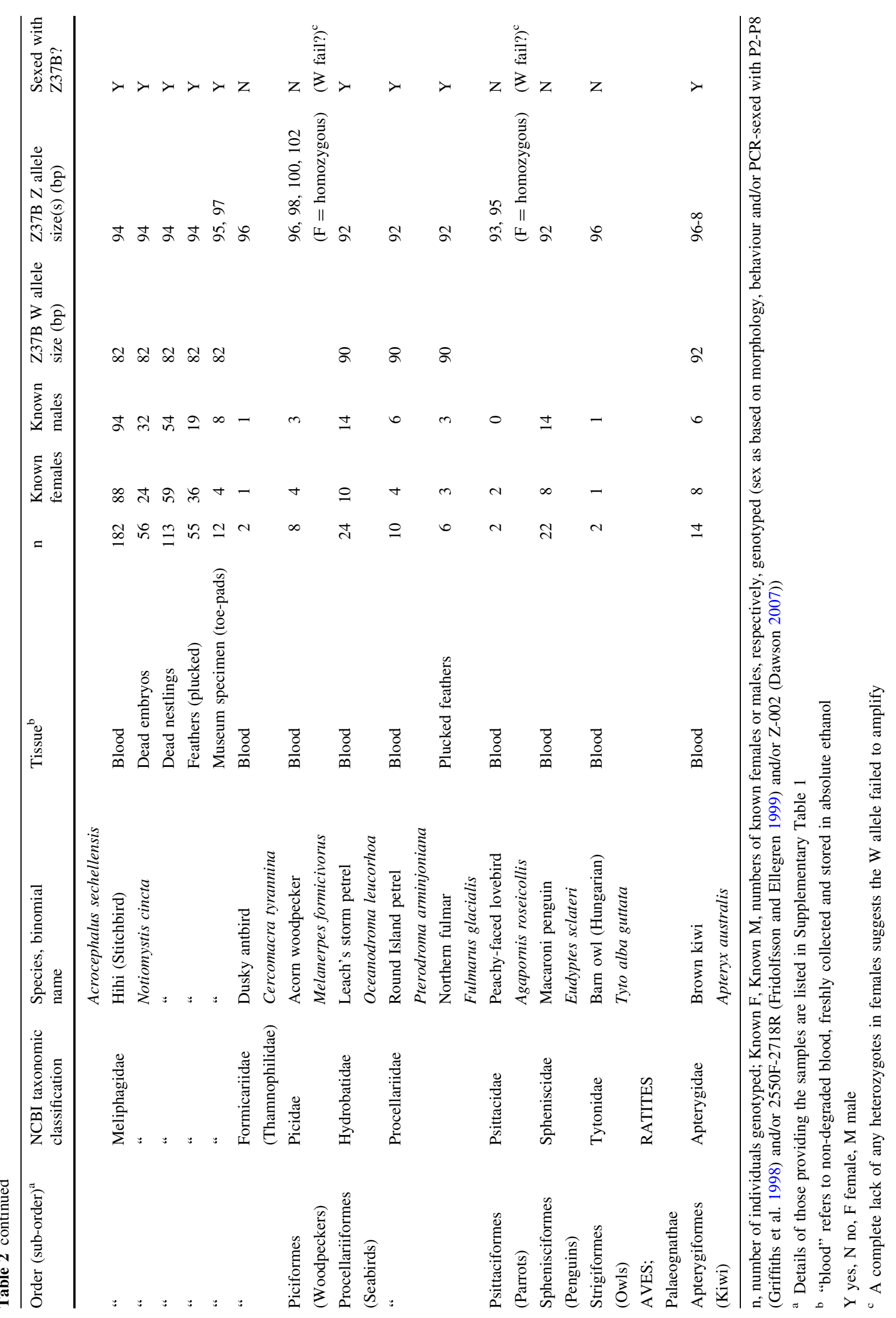


Acknowledgments We thank all those who kindly supplied samples, without which this work would not have been possible (identified in Supplementary Table 1). We are especially grateful to the Maori Leaders' Council, Karori Wildlife Sanctuary, John Ewen, the Zoological Society of London, supporters of Tiritiri Matangi and the Department of Conservation of New Zealand for providing support and sampling permits. We also thank many colleagues who provided their unpublished sex-typing data obtained using available markers (identified in Supplementary Table 1). Z37B data was kindly provided by Sophie Ahmed, Alex Ball, Anthony Bicknell, Susannah Bird, Terry Burke, Lindsay Farrell, Tom Hart, Ben Hatchwell, Jenny Kaden and Jennifer Smith. Douglas Ross and Terry Burke provided comments on the manuscript. This work was performed at the NERC Biomolecular Analysis Facility at Sheffield and was supported by the UK Natural Environment Research Council.

Open Access This article is distributed under the terms of the Creative Commons Attribution License which permits any use, distribution, and reproduction in any medium, provided the original author(s) and the source are credited.

\section{References}

Brekke P, Bennett PM, Wang J, Pettorelli N, Ewen JG (2010) Sensitive males: inbreeding depression in an endangered bird. Proc R Soc Lond B 277:3677-3684

Dawson DA (2007) Genomic analysis of passerine birds using conserved microsatellite loci. PhD Thesis, University of Sheffield, UK

Dawson DA, Darby S, Hunter FM, Krupa AP, Jones IL, Burke T (2001) A critique of CHD-based molecular sexing protocols illustrated by a Z-chromosome polymorphism detected in auklets. Mol Ecol Notes 1:201-204
Dawson DA, Horsburgh GJ, Küpper C, Stewart IRK, Ball AD, Durrant KL, Hansson B, Bacon I, Bird S, Klein Á, Lee J-W, Martín-Gálvez D, Simeoni M, Smith G, Spurgin LG, Burke T (2010) New methods to identify conserved microsatellite loci and develop primer sets of high utility - as demonstrated for birds. Mol Ecol Resour 10:475-494

Fridolfsson AK, Ellegren H (1999) A simple and universal method for molecular sexing of non-ratite birds. J Avian Biol 30:116-121

Griffiths R, Double MC, Orr K, Dawson RJG (1998) A DNA test to sex most birds. Mol Ecol 7:1071-1075

Joint Working Group on Refinement (2001) Laboratory birds: refinements in husbandry and procedures. Fifth report of BVAAWF/FRAME/RSPCA/UFAW. Lab Anim 35:1-163

Kumar S, Tamura K, Nei M (2004) MEGA3: integrated software for Molecular Evolutionary Genetics Analysis and sequence alignment. Brief Bioinform 5:150-163

Price T, Birch GL (1996) Repeated evolution of sexual color dimorphism in passerine birds. Auk 113:842-848

Replogle K, Arnold AP, Ball GF et al (2008) The Songbird Neurogenomics (SoNG) initiative: community-based tools and strategies for study of brain gene function and evolution. BMC Genom 9:131

Richardson DS, Jury FL, Blaakmeer K, Komdeur J, Burke T (2001) Parentage assignment and extra-group paternity in a cooperative breeder: the Seychelles warbler (Acrocephalus sechellensis). Mol Ecol 10:2263-2273

Robertson BC, Gemmell NJ (2006) PCR-based sexing in conservation biology: wrong answers from an accurate methodology? Conserv Genet 7:267-271

Rozen S, Skaletsky HJ (2000) In: Krawetz S, Misener S (eds) Bioinformatics methods and protocols methods in molecular biology. Humana Press, Totowa, pp 365-386

Toouli CD, Turner DR, Grist SA, Morley AA (2000) The effect of cycle number and target size on polymerase chain reaction amplification of polymorphic repetitive sequences. Anal Biochem 280:324-326 